\title{
IMPLIKASI GREEN BRAND IMAGE, GREEN SATISFACTION DAN GREEN TRUST TERHADAP LOYALITAS PELANGGAN (Studi Kasus Pada Konsumen AMDK Galon Merk AQUA di Wilayah Serpong Utara)
}

\author{
Rina Astini \\ Fakultas Ekonomi \& BisnisUniversitas Mercu Buana \\ Email: rinaastini09@gmail.com
}

\begin{abstract}
The Purpose of this study is to know the impacts of green brand image and green satisfaction on green trust and its implication on the customer's loyalty on gallon bottled mineral water products AQUA at North Serpong, South Tangerang. Data were collected from 150 respondents who consume gallon bottled mineral water products AQUA at North Serpong, South Tangerang using a questionnaire. Data analysis which is used is statistical analysis in the form of Structural Equation Modeling. The results indicated that green brand image does significantly affect green satisfaction, while green brand image does negative affect green trust. Green satisfaction does significantly affect green trust, and green trust does significantly affect customer's loyalty on gallon bottled mineral water products AQUA at North Serpong, South Tangerang.
\end{abstract}

Keywords: Green Brand Image, Green Satisfaction, Green Trust, Customer Loyalty

\begin{abstract}
Abstrak: Penelitian ini bertujuan untuk mengetahui pengaruh green brand image dan green satisfaction terhadap green trust serta implikasinya terhadap customer loyalty pada produk air mineral kemasan galon AQUA di wilayah Sepong Utara, Tangerang Selatan. Data dikumpulkan melalui 150 responden yang mengkonsumsi air mineral kemasan galon AQUA dengan menggunakan kuesioner di Serpong Utara. Analisis data yang digunakan adalah analisis statistik dalam bentuk Structural Equation Modeling. Hasil penelitian ini menunjukkan bahwa green brand image berpengaruh signifikan terhadap green satisfaction, sementara green brand image berpengaruh negatif terhadap green trust. Green satisfaction berpengaruh signifikan terhadap green trust, dan green trust berpengaruh signifikan terhadap customer loyalty pada produk air mineral kemasan galon AQUA di wilayah Sepong Utara, Tangerang Selatan.
\end{abstract}

Kata kunci: Green Brand Image, Green Satisfaction, Green Trust, Customer Loyalty.

\section{PENDAHULUAN}

Lingkungan merupakan faktor penting dalam sebuah kehidupan. Lingkungan merupakan hal yang memiliki pengaruh besar dalam sebuah kehidupan makhluk hidup. Keberadaan serta kondisi sebuah lingkungan merupakan hal penting yang harus diperhatikan, dirawat, serta dilestarikan dengan sebaik-baiknya. Kesadaran diri untuk berkomitmen tinggi dalam melestarikan lingkungan merupakan faktor penting.

Dalam dunia bisnis saat ini, aspek lingkungan sudah mulai dijadikan faktor penting yang harus dipertimbangkan dalam melakukan aktivitas pemasaran. Kaufmann, (2012), menyatakan bahwa perlu adanya pengintegrasian konsep pemasaran hijau ke dalam semua aspek kegiatan pemasaran secara rutin.Berkaitan dengan hal tersebut, dalam dunia bisnis 
saat ini banyak para pelaku bisnis yang menjadikan lingkungan sebagai aspek penting yang perlu diikutsertakan dalam menjalankan aktivitas pemasaran. Dengan demikian, pihak pelaku bisnis akan berlomba-lomba untuk menghasilkan sekaligus memasarkan produk dengan konsep produk ramah lingkungan. Selain untuk memenuhi kebutuhan dan keinginan konsumen, dengan konsep Green Marketing tersebut perusahaan dapat serta merta meningkatkan Brand Image perusahaan yang jauh lebih baik yang tentunya dengan aktivitas pemasaran yang ramah lingkungan. Adapun konsep pemaran ramah lingkungan yang banyak dilakukan para pelaku bisnis sering disebut dengan Green Marketing.Green Marketing ialah pemasaran produk yang ramah lingkungan, menggabungkan beberapa aktivitas seperti modifikasi produk, perubahan proses produksi, kemasan, strategi iklan dan juga meningkatkan kesadaran pada pemasaran kepatuhan antara industri.

Setiap perusahaan memiliki cara yang berbeda-beda dalam melakukan kegiatan green marketing. Salah satu kegiatan green marketing yang dapat dijadikan contoh yakni kegiatan green marketing yang dilakukan oleh PT Golden Missisipi yang memiliki produk AMDK (Air Minum Dalam Kemasan) dengan merek AQUA. AQUA merupakan produk ramah lingkungan. aspek ramah lingkungan tersebut diimplementasikan mulai dari aksinya dengan meminimalisir jejak karbon. Pengurangan jejak karbon dilakukan dengan cara audit lingkungan hijau, penghematan energi, penghematan penggunaan listrik yang sudah mengalami penurunan sebesar $6 \%$, serta penghematan bahan baku plastik (kemasan). AQUA menggunakan plastik daur ulang dalam pengemasannya. Selain itu, AQUA juga mempunyai pabrik hijau yang mengalokasikan sebesar $60 \%$ untuk lahan terbuka hijau.

Penelitian ini bertujuan untuk mengkaji dan menganalisis: (1) Pengaruh Green Brand Imageterhadap Green Satisfaction produk AQUA galon; (2) Pengaruh Green Brand Image dan Green Satisfaction berpengaruh terhadap Green Trust produk AQUA galon; (3) Pengaruh Green Trust terhadap Customer Loyalty produk AQUA galon.

\section{KAJIAN TEORI}

Green Marketing. Green Marketing sebagai tindakan yang dilakukan oleh organisasi yang khawatir akan masalah ekologi atau masalah lingkungan, dengan meningkatkan produk ramah lingkungan atau dengan kegiatan yang dapat memberi kepuasan terhadap konsumen dan masyarakat. Terdapat perbedaan antara Traditional Marketing dengan Green Marketing. Perbedaannya bahwa Green Marketing bukan hanya sekedar kegiatan pemasaran yang hanya bersifat komersial namun Green Marketing menjadikan aspek lingkungan sebagi hal yang penting yang harus diperhatikan dalam kegiatan pemasarannya. (Punitha, 2013)

Green Consumer Behavior. Perilaku konsumen merupakan semua kegiatan, tindakan, serta proses psikologi yang mendorong tindakan tersebut pada saat sebelum membeli, ketika membeli, menggunakan, menhabiskan produk dan jasa setelah melakukan hal-hal diatas atas atau kegiatan mengevaluasi (Massie, 2013)

Menurut AMA (American Marketing Association) mendefinisikan perilaku konsumen sebagai sebuah interaksi dinamis antara kognitif, perilaku, dan lingkungannya dimana manusia melakukan kegiatan pertukaran dalam hidup mereka. (Supranto, 2013)

Green Consumer Behavior adalah konsumen yang memiliki kepedulian terhadap lingkungan dan memiliki kecenderungan untuk memilih dan membeli produk ramah 
lingkungan dalam memenuhi kebutuhan dan keinginannya, dan sekaligus akan mendukung bisnis yang berkaitan dengan lingkungan (Kaufimann, 2012).

Green Brand Image. Keberadaan merek pada suatu produk merupakan hal yang sangat penting untuk diperhatikan perusahaan. Hal tersebut dikarenakan dengan adanya sebuah merek pada suatu produk dapat menimbulkan sekaligus meninggalkan pesan pada benak konsumen yang mengetahuinya. Dengan adanya pesan atau kesan pada konsumen itulah yang berpeluang besar untuk menciptakan citra merek (brand image).

Green Brand Image merupakan sebuah persepsi sebuah merek yang ada pada benak konsumen yang berkaitan dengan hal yang menggabungkan antara komitmen dengan kepedulian terhadap lingkungan (Chen 2009).

Green Satisfaction. Green Satisfaction sebagai tingkat pemenuhan konsumsi yang menyenangkan terkait untuk memuaskan keinginan pelanggan pada lingkungan, harapan berkelanjutan dan kebutuhan produk hijau (Chen et al., 2013). Green Satisfaction adalah kepuasan yang terasa ketika salah satu keinginan, kebutuhan atau harapan tentang perlunya produk ramah lingkungan telah terpenuhi (Saleem, 2015).

Green Trust. Kepercayaan merupakan salah satu faktor utama yang mempengaruhi pembelian. Kepercayaan mengacu pada keyakinan individu bahwa konsumen akan berperilaku berdasarkan harapannya. Kepercayaan mengacu pada keyakinan individu bahwa konsumen akan berperilaku berdasarkan harapannya. Kepercayaan konsumen adalah dasar pertimbangan dan harapan konsumen dengan tingkat kepercayaan diri dalam harapan kepada pihak lain yang akan mengarah pada perilaku konsumen jangka panjang (Pratama, 2014).

Green Trust adalahdorongan bagi konsumen untuk memilikikepercayaan pada produk yang memiliki klaim ramah lingkungan (Chen 2015). Green Trust dapat diidentifikasisebagai kecenderungan pelanggan untuk percaya bahwa merek tetappada janjinya mengenai kinerja hijau (green performance).

Konsumen tidak akan mempercayai kegiatan perusahaan yang ramah lingkungan sampai mereka yakin tentang manfaat yang dihasilkan. Konsumen tidak hanya mengandalkan produk hijau tanpa informasi sebelumnya tentang dampak lingkungan (Chen, 20115).

Customer Loyalty. Loyalitas adalah wujud perilaku dari unit-unit pengambilan keputusan untuk melakukan pembelian secara terus menerus terhadap barang atau jasa suatu perusahaan yang dipilih (Kalalo, 2013).

Loyalitas konsumen pada umunya merupakan suatu sikap yang merujuk pada ukuran keterkaitan konsumen terhadap pemilihan dan penggunaan suatu produk. Ukuran keterkaitan ini memberikan gambaran tentang penggunaan produk dalam waktu yang lama dan untuk masa yang akan datang, serta ukuran ini mampu mencerminkan peluang yang sangat kecil mengenai kemungkinan seorang konsumen beralig kepada penggunaan produk pesaing, apabila produk pesaing tersebut didapati adanya perubahan, baik menyangkut harga maupun atribut produk lainnya. (Hermawan, 2011).

Semakin besar niat pelanggan untuk membeli ulang atau niat untuk merekomendasikan suatu perusahaan jasa memberikan suatu indikasi bahwa perusahaan jasa tersebut mempunyai bisnis yang cerah di masa depan. Sehingga dimensi sikap ini merupakan indikasi yang baik untuk pengukuran loyalitas pelanggan. Dengan kata lain, 
dimensi ini akan memberikan indikasi apakah pelanggan akan tetao membeli lagi atau pindah pada perusahaan jasa lainnya.

Memiliki pelanggan yang loyal adalah salah satu tujuan akhir dari perusahaan karena loyalitas pelanggan dapat menjamin kelanggena hidup perusahaan dalam jangka panjang.

Rerangka Pemikiran dan Hipotesis

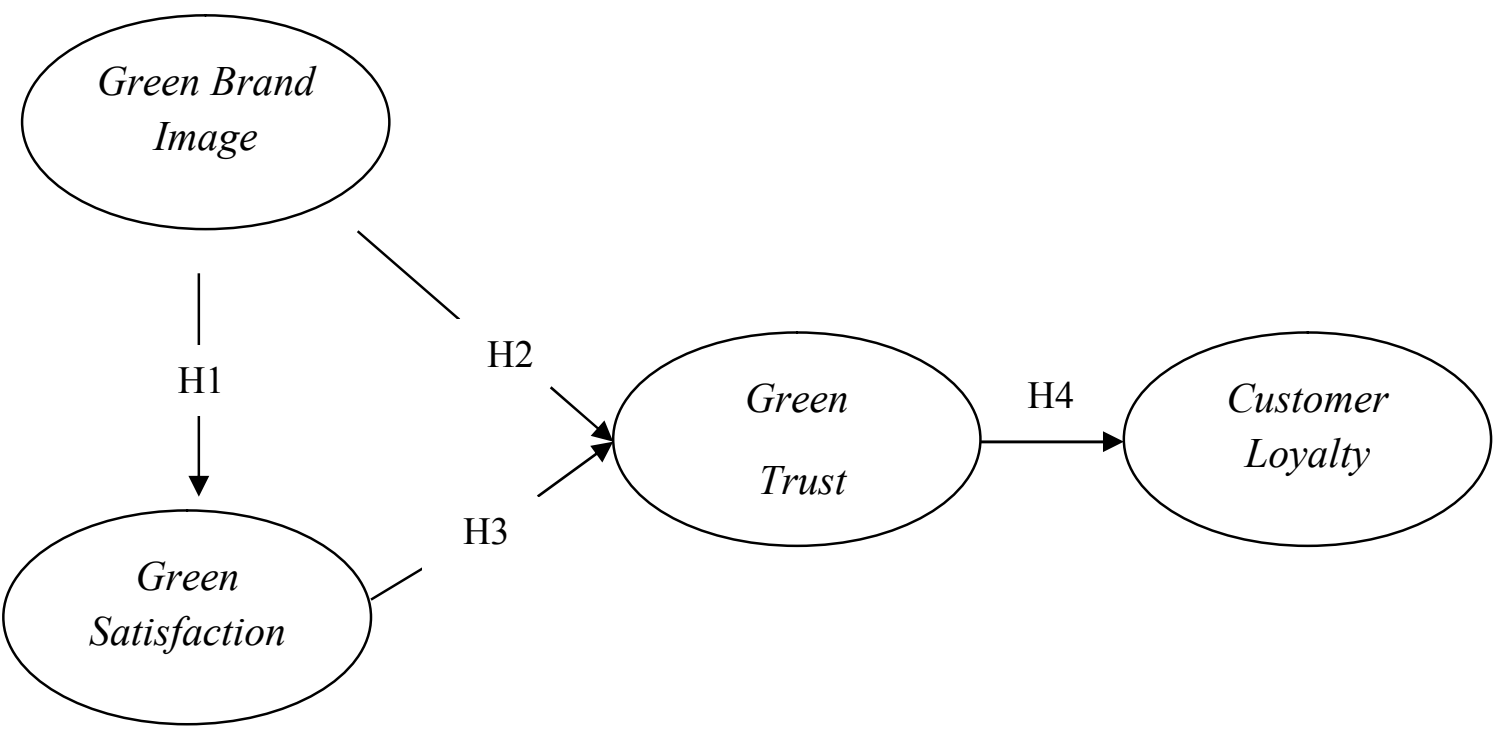

Gambar 1. Rerangka Pemikiran

$\mathrm{H} 1=$ Green Brand Image berpengaruh signifikan terhadap Green Satisfaction

$\mathrm{H} 2$ = Green Brand Image berpengaruh signifikan terhadap Green Trust

H3 = Green Satisfaction berpengaruh signifikan terhadap Green Trust

H4 = Green Trust berpengaruh signifikan terhadap Green Customer Loyalty.

\section{METODE}

Penelitian ini dimulai pada bulan Oktober - November 2015. Objek yang digunakan adalah konsumen rumah tangga yang dalam kehidupan sehari-harinya mengkonsumsi AMDK galon AQUA (minimal 2 galon/bulan) dan berdomisili di wilayah Serpong Utara, Tangerang Selatan. metode yang digunakan adalah metode kausal. Metode analisis kausal adalah desain yang berguna untuk menganalisis hubungan-hubungan antara satu variabel mempengaruhi variabel lainnya. Green brand image merupakanvariabel eksogen, Green Satisfaction dan Green Trust merupakan variabel intervening dan Customer Loyalty merupakan variabel endogen.

Populasi dan Sampel. Menurut Hair et al dalam (Noor, 2011) Ukuran sample untuk kepentingan pengujian hipotesis yang menggunkan Structural equation Modeling (SEM) berkisar 100-200. Pedomannya adalah 5-10 kali jumlah parameter diestimasikan. Berdasarkan jumlah indikator dikalikan $5(20$ x $5=100)$. Namun di penelitian ini peneliti mengambil sampel 150 untuk hasil analisis data yang lebih akurat. 
Dalam penelitian ini, peneliti menggunakan Convenience Sampling (Cara Dipermudah) dalam pengambilan sampel. Convenience Sampling merupakan teknik penentuan sampel dengan pertimbangan kemudahan atau kebetulan saja. Sampel dalam penelitian ini adalah konsumen rumah tangga yang dalam kehidupan sehari-harinya mengkonsumsi AMDK galon AQUA (minimal 2 galon/bulan) dan berdomisili di wilayah Serpong Utara, Tangerang Selatan.

Definisi dan Operasional Variabel

Tabel 1. Definisi Operasional Variabel

\begin{tabular}{|c|c|c|c|}
\hline Variabel & Dimensi & Indikator & Skala \\
\hline $\begin{array}{l}\text { Green Brand } \\
\text { Image } \\
\text { (Independen) }\end{array}$ & - & $\begin{array}{l}\text { a. Mempunyai kredibilitas tinggi } \\
\text { dalam menjaga komitmen baiknya } \\
\text { terhadap lingkungan. }\end{array}$ & Ordinal \\
\hline \multirow{4}{*}{$\begin{array}{l}\text { Sumber : } \\
\text { Chen, (2009) }\end{array}$} & & $\begin{array}{l}\text { b. Merek memiliki reputasi yang } \\
\text { baik terhadap lingkungan. }\end{array}$ & Ordinal \\
\hline & & $\begin{array}{l}\text { c. Merek memiliki kesuksesan dalam } \\
\text { menjaga lingkungan. }\end{array}$ & Ordinal \\
\hline & & $\begin{array}{l}\text { d. Merek memiliki kepedulian tinggi } \\
\text { terhadap lingkungan. }\end{array}$ & Ordinal \\
\hline & & $\begin{array}{l}\text { e. Janji yang dimiliki merek dapat } \\
\text { dipercaya dalam menjaga } \\
\text { kelestarian lingkungan. }\end{array}$ & Ordinal \\
\hline $\begin{array}{l}\text { Green } \\
\text { Satisfaction } \\
\text { (Intervening) }\end{array}$ & $\begin{array}{l}\text { Kebahagiaan dalam } \\
\text { memutuskan } \\
\text { memilih merek hijau }\end{array}$ & $\begin{array}{l}\text { a. Kesenangan dalam memutuskan } \\
\text { untuk memilih merek yang } \\
\text { berkomitmen terhadap } \\
\text { lingkungan. }\end{array}$ & Ordinal \\
\hline $\begin{array}{l}\text { Sumber : } \\
\text { Chen (2013) }\end{array}$ & $\begin{array}{l}\text { Kepercayaan } \\
\text { membeli merek } \\
\text { hijau yang tepat }\end{array}$ & $\begin{array}{l}\text { a. Kepercayaan membeli merek yang } \\
\text { memiliki kinerja terhadap } \\
\text { lingkungan adalah hal yang tepat. }\end{array}$ & Ordinal \\
\hline \multirow[t]{2}{*}{ Chen (2009) } & $\begin{array}{l}\text { Kesenangan } \\
\text { membeli merek } \\
\text { hijau }\end{array}$ & $\begin{array}{l}\text { a. Kesenangan untuk membeli merek } \\
\text { yang ramah lingkungan.. }\end{array}$ & Ordinal \\
\hline & $\begin{array}{l}\text { Kepuasan membeli } \\
\text { merek hijau }\end{array}$ & $\begin{array}{l}\text { a. Kepuasan terhadap merek yang } \\
\text { memiliki kepedulian terhadap }\end{array}$ & Ordinal \\
\hline
\end{tabular}


lingkungan.

\begin{tabular}{|c|c|c|c|c|}
\hline $\begin{array}{l}\text { Green Trust } \\
\text { (Variabel } \\
\text { Intervening) }\end{array}$ & $\begin{array}{l}\text { Perasaan bahwa } \\
\text { komitmen hijau dan } \\
\text { merek dapat } \\
\text { diandalkan. }\end{array}$ & a. & $\begin{array}{l}\text { Komitmen merek terhadap } \\
\text { lingkungan dapat diandalkan. }\end{array}$ & Ordinal \\
\hline Sumber : & $\begin{array}{l}\text { Perasaan tergantung } \\
\text { pada kinerja merek }\end{array}$ & a. & $\begin{array}{l}\text { Kinerja merek terhadap } \\
\text { lingkungan umumnya dapat } \\
\text { dipertanggung jawabkan. }\end{array}$ & Ordinal \\
\hline Chen (2013) & $\begin{array}{l}\text { Perasaan bahwa } \\
\text { argument } \\
\text { kelingkunganan } \\
\text { dapat dipercaya }\end{array}$ & a. & $\begin{array}{l}\text { Argument kelingkunganan yang } \\
\text { dimiliki merek dapat dipercaya. }\end{array}$ & Ordinal \\
\hline Chen (2009) & $\begin{array}{l}\text { Perhatian } \\
\text { kelingkunganan } \\
\text { merek sesuai } \\
\text { harapan }\end{array}$ & a. & $\begin{array}{l}\text { Kepedulian kelingkunganan } \\
\text { merek memenuhi harapan. }\end{array}$ & Ordinal \\
\hline & $\begin{array}{l}\text { Merek memegang } \\
\text { janji dan komitmen } \\
\text { perlindungan } \\
\text { kelingkunganan }\end{array}$ & a. & $\begin{array}{l}\text { Merek memegang janji dan } \\
\text { komitmen untuk memberikan } \\
\text { perlindungan terhadap } \\
\text { lingkungan. }\end{array}$ & Ordinal \\
\hline \multirow{2}{*}{$\begin{array}{l}\text { Consumer } \\
\text { Loyalty } \\
\text { (Dependen) }\end{array}$} & Re-Purchase & a. & $\begin{array}{l}\text { Melakukan pembelian secara } \\
\text { kontinyu }\end{array}$ & Ordinal \\
\hline & Paymore & a. & Membeli jasa layanan tambahan & Ordinal \\
\hline $\begin{array}{l}\text { Sumber : } \\
\text { Kalalo (2013) }\end{array}$ & Advocate & b. & $\begin{array}{l}\text { Merekomendasikan penyedia jasa } \\
\text { kepada orang lain } \\
\text { Menyampaikan hal positif } \\
\text { penyedia jasa ke orang lain. } \\
\text { Kesediaan berbagi informasi }\end{array}$ & Ordinal \\
\hline
\end{tabular}

Retention

a. Menguji jasa layanan baru

Ordinal

Jenis Data dan Pengukuran. Jenis dan sumber data adalah data primer. Data primer diperoleh dari hasil wawancara responden dengan menggunakan kuesioner. Pengukuran data yang dilakukan dalam penelitian ini adalah dengan menggunakan skala likert. Skala likert digunakan untuk mengukur sikap dalam suatu penelitian. Pemberian kode angka adalah sebagai berikut (Sugiyono, 2014:168): (a) 1 = Sangat tidak setuju; (b) 2 = Tidak setuju; (c) 3 = Netral; (d) 4 = Setuju; (e) 5 = Sangat setuju. 
Metode Statistik. Pengukuran konstruk dan hubungan antar variabel akan dinilai dengan menggunakanModel Persamaan Struktural (Structural Equation Modellilng SEM)dengan menggunakan program LISREL 8.8.SEM adalah generasi kedua teknik analisis multivariate yang memungkinkan peneliti untuk menguji hubungan antara variabel yang kompleks baik recursive maupun non-recursive untuk memperoleh gambaran menyeluruh mengenai keseluruhan model (Ghozali, 2005).

\section{HASIL DAN PEMBAHASAN}

Karakteristik Responden. Jumlah responden yang berpartisipasi mengisi kesioner penelitian ini berjumlah 150 responden. Untuk statistik deskriptif terdapat 19 pernyataan yang masing-masing mewakili setiap variabel yang ada, antara lain: 5 pernyataan mengenai green brand image; 4 pernyataan mengenai green satisfaction; 5 pernyataan mengenai green trust; dan 5 pernyataan mengenai customer loyalty.Berikut ini adalah hasil analisis statistik deskriptif responden, diantaranya:

Tabel 2. Hasil Statistik Deskriptif Responden

\begin{tabular}{|c|c|c|c|}
\hline \multicolumn{2}{|r|}{ Karakteristik } & Frekuensi & Persen \\
\hline \multirow{5}{*}{$\begin{array}{c}\text { Alamat } \\
\text { Responden }\end{array}$} & 1. Alam Sutera & 39 & $26 \%$ \\
\hline & 2. Villa Melati Mas & 16 & $10,7 \%$ \\
\hline & 3. Melati Mas Regency & 18 & $12 \%$ \\
\hline & 4. Graha Raya & 63 & $42 \%$ \\
\hline & 5. Royal Serpong Village & 14 & $9,3 \%$ \\
\hline \multirow{2}{*}{ Jenis Kelamin } & 1. Laki-laki & 61 & $40,7 \%$ \\
\hline & 2. Perempuan & 89 & $59,3 \%$ \\
\hline \multirow{4}{*}{ Usia Responden } & 1. $\leq 20$ tahun & 42 & $28 \%$ \\
\hline & 2. 21-30 tahun & 96 & $64 \%$ \\
\hline & 3. $31-40$ & 5 & $3,3 \%$ \\
\hline & 4. $\geq 41$ tahun & 7 & $4,7 \%$ \\
\hline \multirow{6}{*}{$\begin{array}{l}\text { Pekerjaan } \\
\text { Responden }\end{array}$} & 1. Pelajar/mahasiswa & 59 & $39,3 \%$ \\
\hline & 2. PNS & 3 & $2 \%$ \\
\hline & 3. Wiraswata & 71 & $8 \%$ \\
\hline & 4. Lainnya & 12 & $2 \%$ \\
\hline & 5. Pegawai Swasta & 2 & $47,3 \%$ \\
\hline & 6. Ibu rumah tangga & 3 & $1,3 \%$ \\
\hline \multirow{3}{*}{$\begin{array}{c}\text { Pendidikan } \\
\text { Terakhir }\end{array}$} & 1. SMA/sederajat & 97 & $64,7 \%$ \\
\hline & 2. Diploma & 13 & $8,7 \%$ \\
\hline & 3. Sarjana & 40 & $47,3 \%$ \\
\hline \multirow{5}{*}{$\begin{array}{c}\text { Penghasilan } \\
\text { Perbulan }\end{array}$} & 1. $\quad<$ Rp.1.000.000, & & \\
\hline & 2. Rp $1.000 .000,-$ s.d Rp & 39 & $26 \%$ \\
\hline & $3.000 .000,-$ & 40 & $26,7 \%$ \\
\hline & 3. Rp 3.000.000,- s.d Rp & 39 & $26 \%$ \\
\hline & 5.000.000,-. & 32 & $21,3 \%$ \\
\hline
\end{tabular}

Sumber: Hasil pengolahan dengan program SPSS

Uji Validitas Variabel. Sebelum dilakukan analisis data perlu dilakukan uji measurement yang berupa uji validitas dan uji reabilitas terhadap alat pengumpulan data yaitu kuesioner 
yang diisi oleh responden. Uji validitas digunakan dalam penelitian untuk mengetahui sejauh mana ketpatan dan kecermatan suatu lat ukur dalam melakukan fungsi ukurnya.

Pengujian validitas dilakukan menggunakan analisis konfirmatori. Dalam analisis konfirmator, variabel laten dianggap sebagai variabel penyebab yang mendasari indikatorindikatornya (Ghozali, 2008). Dasar pengambilan keputusan uji validitas ini adalah jika Loading factor $\geq 0,5$ maka item tersebut dikatakan valid.

Tabel 3. Hasil Uji Validitas Variable

\begin{tabular}{cccc}
\hline Variabel & Indikator & $\begin{array}{c}\text { Standardize Loading } \\
\text { Factor (SLF) }\end{array}$ & Kesimpulan \\
\hline \multirow{5}{*}{ Green Brand Image } & GBI_1 & 0,76 & VALID \\
& GBI_2 & 0,68 & VALID \\
& GBI_3 & 0,66 & VALID \\
& GBI_4 & 0,75 & VALID \\
& GBI_5 & 0,72 & VALID \\
Green Satisfaction & GS_1 & 0,80 & VALID \\
& GS_2 & 0,76 & VALID \\
& GS_3 & 0,59 & VALID \\
Green Trust & GS_4 & 0,74 & VALID \\
& GT_1 & 0,62 & VALID \\
& GT_2 & 0,70 & VALID \\
& GT_3 & 0,78 & VALID \\
& GT_4 & 0,83 & VALID \\
& GT_5 & 0,66 & VALID \\
Customer Loyalty & CL_1 & 0,70 & VALID \\
& CL_2 & 0,39 & TIDAK VALID \\
& CL_3 & 0,80 & VALID \\
& CL_4 & 0,80 & VALID \\
& CL_5 & 0,67 & VALID \\
\hline
\end{tabular}

Uji validitas dilakukan terhadap masing-masing butir pernyataan variabel green brand image, green satisfaction, green trust dan customer loyalty. Uji validitas dengan analisis faktor konfirmatori terhadap variabel dalam penelitian ini terdapat indikator yang tidak valid dengan nilai standardize Loading Factor $\leq 0,50$ yaitu indikator CL_2 (Kemasan yang berbeda). Selebihnya indikator dalam penelitian ini dikatakan valid dan dapat dipakai dalam penelitian ini. Indikator yang tidak valid tidak akan digunakan dalam penelitian.

Uji Reabilitas Variabel. Reliabilitas adalah ukuran mengenai konsistensi internal dari indikator sebuah variabel yang menunjukan derajat masing-masing indikator itu mengindikasikan sebuah konstruk / faktor laten yang umum. Pengujian reliabilitas instrumen bertujuan untuk mengetahui konsistensi suatu instrumen. Langkah selanjutnya adalah menghitung loadings dan menilai signifikansi statistik setiap indikator. Jika terbukti tidak signifikan, maka indikator harus dibuang atau mentransformasikannya agar menjadi fit untuk variabel laten (Noor, 2011).

Dari perhitungan diatas maka diketahui bahwa keempat variabel yang digunakan dalam penelitian ini memiliki nilai construct reliability lebih besar dari 0,7 maka dengan demikian keempat variabel dikatakan reliable. 
Tabel 4. Hasil Uji Reabilitas Variabel

\begin{tabular}{cccc}
\hline Variabel & $\begin{array}{c}\text { Construct } \\
\text { Reability }\end{array}$ & $\begin{array}{c}\text { Variance } \\
\text { Extracted }\end{array}$ & Kesimpulan \\
\hline Green Brand Image & 0,83 & 0,51 & Reliabel \\
Green Satisfaction & 0,81 & 0,51 & Reliabel \\
Green Trust & 0,80 & 0,52 & Reliabel \\
Customer Loyalty & 0,83 & 0,55 & Reliabel \\
\hline
\end{tabular}

Selanjutnya, dapat diketahui bahwa keempat variabel yang digunakan dalam penelitian ini memiliki nilai variance extract lebih besar dari 0,5 maka dengan demikian keempat variabel dikatakan reliable. Dengan demikian, berdasarkan kedua perhitungan tersebut dapat disimpulkan bahwa keempat variabel dalam penelitian ini (green brand image, green satisfaction, green trust dan customer loyalty) dikatakan reliable dan dapat digunakan dalam penelitian ini.

\section{Uji Kecocokan Keseluruhan Model Pengukuran}

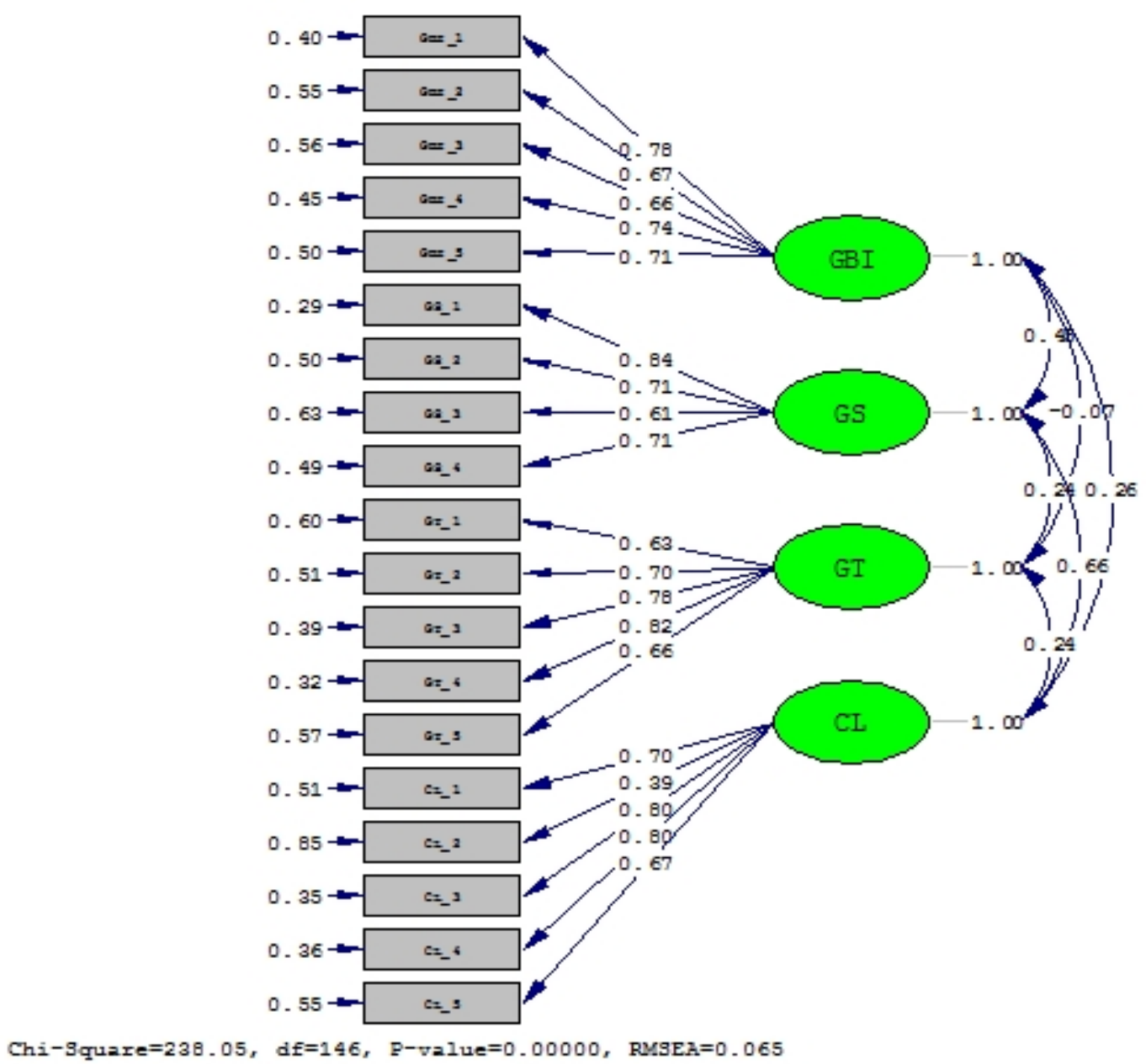

Gambar 2. Model Pengukuran Keseluruhan Variabel Penelitian 
Tabel 5. Hasil Uji Kecocokan Model pengukuran

\begin{tabular}{clccc}
\hline No & \multicolumn{1}{c}{ Ukuran GOF } & $\begin{array}{c}\text { Tingkat Target } \\
\text { Kecocokan }\end{array}$ & $\begin{array}{c}\text { Hasil } \\
\text { Estimasi }\end{array}$ & $\begin{array}{c}\text { Tingkat } \\
\text { Kecocokan }\end{array}$ \\
\hline 1. & $\begin{array}{l}\text { Root Mean Square Error of } \\
\text { Appoximation (RMSEA) }\end{array}$ & $\begin{array}{c}\text { RMSEA } \leq 0,08 \\
\mathrm{P} \geq 0,50\end{array}$ & 0,065 & Good Fit \\
2. & $\begin{array}{l}\text { P (close fit) } \\
\text { Normed Fit Index(NFI) }\end{array}$ & $\mathrm{NFI} \geq 0,90$ & 0,89 & Marginal Fit \\
3. & Non-Noormed Fit Index (NNFI) & $\mathrm{NNFI} \geq 0,90$ & 0,94 & Good Fit \\
4. & Comparative Fit Index (CFI) & $\mathrm{CFI} \geq 0,90$ & 0,95 & Good Fit \\
5. & Incremental Fit Index (IFI) & $\mathrm{IFI} \geq 0,90$ & 0,95 & Good Fit \\
6. & Relative Fit Index (RFI) & $\mathrm{RFI} \geq 0,90$ & 0,87 & Marginal Fit \\
7. & Goodness of Fit Index (GFI) & $\mathrm{GFI} \geq 0,90$ & 0,86 & Marginal Fit \\
8. & Adjusted Goodness of Fit Index & $\mathrm{AGFI} \geq 0,90$ & 0,82 & Marginal Fit \\
& (AGFI) & & & \\
\hline
\end{tabular}

Model pengukuran konstruk variabel penelitian tersebut Good Fit karena memiliki nilai RMSEA $\leq 0,08$ yaitu sebesar 0,065 sehingga tidak diperlukan adanya modifikasi model.

\section{Uji Kecocokan Model Struktural (Uji T)}

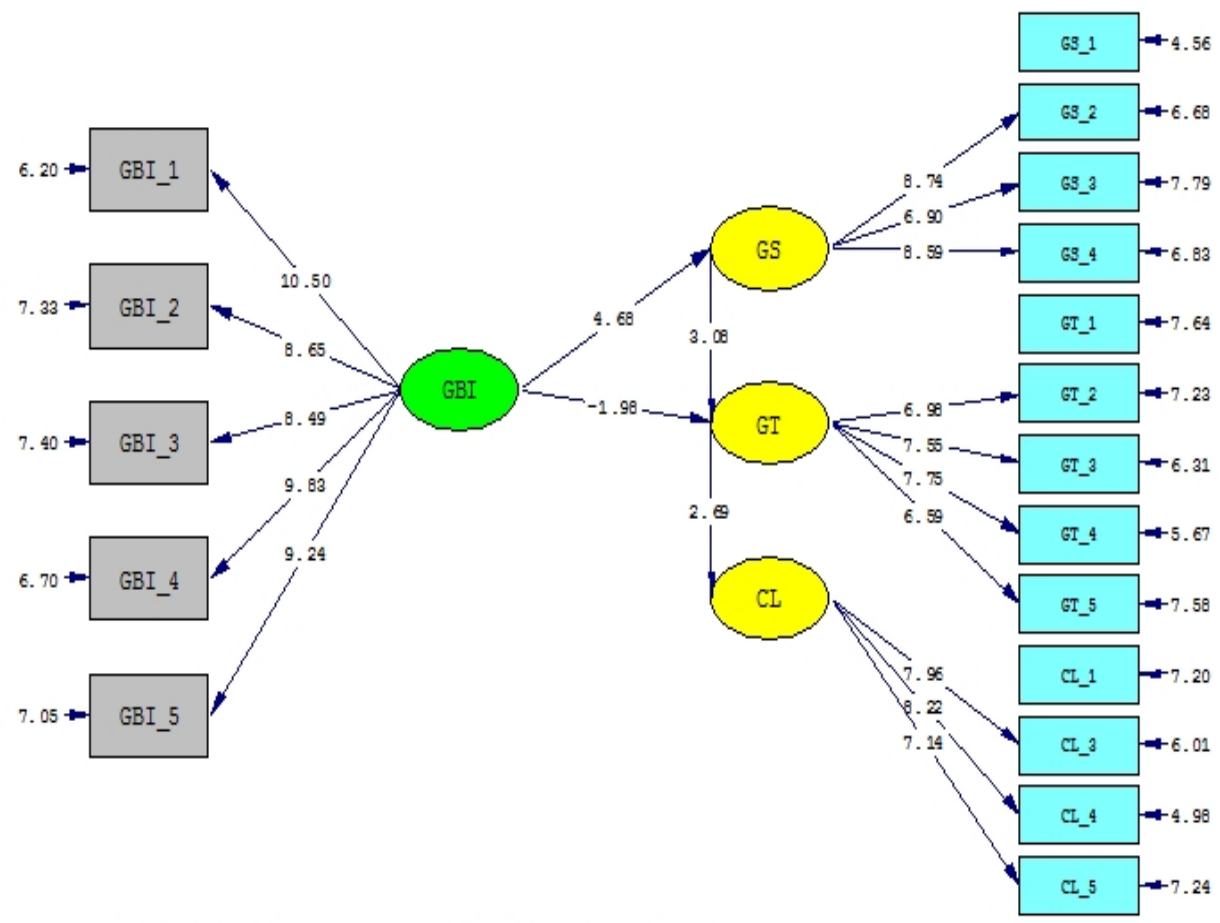

Chi-8quare $=245.36, d f=131, p-v a l u e=0.00000$, RMSEA $=0.077$

Gambar 6. Uji Model Struktural (T-Value) 
Tabel 6. Hasil Uji Kecocokan Struktural Model Penelitian

\begin{tabular}{llccc}
\hline No & \multicolumn{1}{c}{ Ukuran GOF } & $\begin{array}{c}\text { Tingkat Target } \\
\text { Kecocokan }\end{array}$ & $\begin{array}{c}\text { Hasil } \\
\text { Estimasi }\end{array}$ & $\begin{array}{c}\text { Tingkat } \\
\text { Kecocokan }\end{array}$ \\
\hline 1. & $\begin{array}{l}\text { Root Mean Square Error of } \\
\text { Appoximation (RMSEA) P (close }\end{array}$ & $\begin{array}{c}\text { RMSEA } \leq 0,08 \\
\mathrm{P} \geq 0,50\end{array}$ & 0,077 & Good Fit \\
& Fit) & $\mathrm{NFI} \geq 0,90$ & 0,86 & Marginal Fit \\
2. & Normed Fit Index(NFI) & $\mathrm{NNFI} \geq 0,90$ & 0,91 & Good Fit \\
3. & Non-Noormed Fit Index (NNFI) & $\mathrm{CFI} \geq 0,90$ & 0,92 & Good Fit \\
4. & Comparative Fit Index (CFI) & $\mathrm{IFI} \geq 0,90$ & 0,92 & Good Fit \\
5. & Incremental Fit Index (IFI) & $\mathrm{RFI} \geq 0,90$ & 0,84 & Marginal Fit \\
6. & Relative Fit Index (RFI) & $\mathrm{GFI} \geq 0,90$ & 0,85 & Marginal Fit \\
7. & Goodnees of Fit Index (GFI) & $\mathrm{AGFI} \geq 0,90$ & 0,80 & Marginal Fit \\
8. & Adjusted Goodness of Fit Index & & & \\
\hline
\end{tabular}

Dari Tabel 6 terlihat bahwa nilai kecocokan model menunjukan nilai yang bagus artinya secara keseluruhan nilai kecocokan menunjukan good fit.

\section{Pengujian Hipotesis}

Tabel 7. Hasil Pengujian Hipotesis Penelitian

\begin{tabular}{|c|c|c|c|c|}
\hline Hipotesis & Structural Path & T-values & Keterangan & Kesimpulan \\
\hline $\mathrm{H} 1$ & $\begin{array}{l}\text { Green Brand Image } \\
\rightarrow \text { Green Satisfaction }\end{array}$ & 4,68 & $\begin{array}{l}\text { Data } \\
\text { mendukung } \\
\text { hipotesis }\end{array}$ & $\begin{array}{l}\text { Green Brand Image } \\
\text { berpengaruh signifikan } \\
\text { terhadap Green Satisfaction }\end{array}$ \\
\hline $\mathrm{H} 2$ & $\begin{array}{l}\text { Green Brand Image } \\
\rightarrow \text { Green Trust }\end{array}$ & $-1,98$ & $\begin{array}{l}\text { Data } \\
\text { mendukung } \\
\text { hipotesis }\end{array}$ & $\begin{array}{l}\text { Green Brand Image } \\
\text { berpengaruh negatif } \\
\text { signifikan terhadap Green } \\
\text { Trust }\end{array}$ \\
\hline $\mathrm{H} 3$ & $\begin{array}{l}\text { Green Satisfaction } \rightarrow \\
\text { Green Trust }\end{array}$ & 3,08 & $\begin{array}{l}\text { Data } \\
\text { mendukung } \\
\text { hipotesis }\end{array}$ & $\begin{array}{l}\text { Green Satisfaction } \\
\text { berpengaruh signifikan } \\
\text { terhadap Green Trust }\end{array}$ \\
\hline $\mathrm{H} 4$ & $\begin{array}{l}\text { Green Trust } \rightarrow \\
\text { Customer Loyalty }\end{array}$ & 2,69 & $\begin{array}{l}\text { Data } \\
\text { mendukung } \\
\text { hipotesis }\end{array}$ & $\begin{array}{l}\text { Green Trust berpengaruh } \\
\text { signifikan terhadap } \\
\text { Customer Loyalty }\end{array}$ \\
\hline
\end{tabular}

Dari Tabel 7 di atas, bisa ditarik kesimpulan mengenai model penelitian untuk variabel Green Satisfaction, ditemukan bahwa Green Brand Image menunjukkan pengaruh yang signifikan terhadap Green Satisfaction, dengan nilai t $<1$, 96, yaitu 4,68. Pada model penelitian Green Trust, yaitu Green Brand Image memiliki pengaruh negatif terhadap Green Trust, ditunjukkan dengan nilai $\mathrm{t}<1,96$, yaitu $-1,98$. Berbeda dengan Green Satisfaction, menunjukkan pengaruh yang signifikan terhadap Green Trust, dengan nilai $\mathrm{t}>1,96$, yaitu 3,08. Pada model penelitian Customer Loyalty, ditemukan bahwa 
Green Trust menunjukkan pengaruh yang signifikan terhadap variabel Customer Loyalty, dimana nilai $\mathrm{t}<1,96$, yaitu 2,69 .

Analisis Green Brand Image Terhadap Green Satisfaction. Berdasarkan Tabel 7 dapat dilihat bahwa variabel Green Brand Image memiliki pengaruh yang signifikan terhadap Green Satisfaction, terlihat dari nilai $\mathrm{t}>1,96$, yaitu 4,68. Hasil ini mengatakan bahwa green brand image yang dimiliki oleh produk AMDK galon AQUA dapat memberikan dampak kepuasan (green satisfaction) dari sisi konsumen. Hasil uji hipotesis ini sejalan dengan hasil penelitian yang dilakukan oleh Yu- Shan Chen (2009) yang menyatakan bahwa green brand image memiliki pengaruh positif dan signifikan terhadap green satisfaction.

Analisis Green Brand Image Terhadap Green Trust. Berdasarkan Tabel 7 dapat dilihat bahwa variabel Green Brand Image memiliki pengaruh yang negatif terhadap Green Trust, terlihat dari nilai $\mathrm{t}>1,96$, yaitu $-1,98$. Berdasarkan hasil uji hipotesis ini menyatakan bahwa green brand image merupakan variabel yang berpengaruh negatif terhadap variabel Green Trust pada produk AMDK galon merek AQUA. Hal ini menunjukkan bahwa semakin tinggi Green Brand Image yang dimiliki oleh produk AMDK galon AQUA, maka semakin kecil tingkat Green Trust yang dimiliki konsumen produk AMDK galon AQUA. Demikian juga sebaliknya, semakin rendah Green Brand Image yang dimiliki oleh produk AMDK galon AQUA, maka semakin tinggi tingkat Green Trust yang dimiliki konsumen produk AMDK galon AQUA. Adapun salah indikator yang memiliki pengaruh negatif dalam hal ini disebabkan oleh reputasi baik yang dimiliki produk AQUA dapat berpengaruh negatif terhadap kepercayaan yang dimiliki konsumen. Dengan tingkat pengetahuan yang dimiliki responden dalam penelitian ini tentu memiliki pengaruh yang cukup besar yang dapat mempengatuhi tingkat kepercayaan konsumen pada produk AMDK galon AQUA. Dalam hal ini, reputasi baik yang dimiliki produk AQUA tidak serta merta dapat meningkatkan tingkat kepercayaan pada konsumen. Hasil uji hipotesis ini tidak sejalan dengan hasil penelitian yang dilakukan oleh Yu-Shan Chen (2013) yang menyatakan bahwa green satisfaction memiliki pengaruh positif dan signifikan terhadap green trust.

Analisis Green Satisfaction Terhadap Green Trust. Berdasarkan Tabel 7 dapat dilihat bahwa variabel Green Satisfaction memiliki pengaruh yang signifikan terhadap Green Trust, terlihat dari nilai $\mathrm{t}>1,96$, yaitu 3,08. Berdasarkan hasil uji hipotesis ini menyatakan bahwa Green Satisfaction merupakan variabel yang berpengaruh terhadap variabel Green Trust pada produk AMDK galon merek AQUA. Hasil uji hipotesis ini sejalan dengan hasil penelitian yang dilakukan oleh Yu-ShanChen (2013) yang menyatakan bahwa green satisfaction memiliki pengaruh positif dan signifikan terhadap green trust.

Analisis Green Trust Terhadap Customer Loyalty. Berdasarkan Tabel 7 dapat dilihat bahwa variabel Green Trust memiliki pengaruh yang signifikan terhadap Customer Loyalty, terlihat dari nilai $\mathrm{t}>1,96$, yaitu 2,69. Hasil ini menegaskan bahwa kepercayaan yang dimiliki konsumen produk ADMK galon AQUA berdampak positif pada keloyalitasan konsumen produk AMDK galon merek AQUA. Hasil uji hipotesis sejalan dengan hasil penelitian yang dilakukan oleh Rina Suthia Hayu (2014) yang menyatakan bahwa green trust memiliki pengaruh yang pengaruh positif dan signifikan terhadap customer loyalty. 


\section{PENUTUP}

Simpulan. Green Brand Image berpengaruh terhadap Green Satisfaction pada produk AMDK galon merek AQUA di wilayah Serpong Utara. Hal ini menunjukkan bahwa green brand image yang dimiliki produk AMDK galon AQUA berdampak pada kepuasan konsumen. Semakin tinggi green brand image yang dimiliki produk AMDK galon AQUA maka kepuasan konsumen terhadap AMDK galon AQUA meningkat.

Green Brand Image berpengaruh negatif terhadap Green Trust menunjukkan pengaruh negatif. Hal ini menunjukkan bahwa semakin tinggi Green Brand Image yang dimiliki oleh produk AMDK galon AQUA, maka semakin kecil tingkat Green Trust yang dimiliki konsumen produk AMDK galon AQUA. Demikian juga sebaliknya, semakin rendah Green Brand Image yang dimiliki oleh produk AMDK galon AQUA, maka semakin tinggi tingkat Green Trust yang dimiliki konsumen produk AMDK galon AQUA. Dengan demikian, perlu adanya strategi yang tepat dengan mengikutsertakan aspek kelestarian lingkungan dalam meningkatkan green brand image produk AQUA. Dengan adanya ketepatan strategi dalam menimbulakn serta meningkatkan green brand image tentu akan memiliki pengaruh besar dalam menimbulkan green trust pada benak konsumen terhadap konsumen produk AMDK galon merek AQUA.

Green Satisfaction berpengaruh terhadap Green Trust pada produk AMDK galon merek AQUA di wilayah Serpong Utara. Hal ini berarti bahwa kepuasan konsumen mempengaruhi tingkat kepercayaan konsumen. Semakin konsumen merasa puas terhadap produk AMDK galon AQUA maka konsumen akan semakin percaya pada produk AMDK galon AQUA. Konsumen yang merasa puas adalah konsumen yang mendapatkan sesuatu yang sesuai dengan apa yang diharapkan ketika konsumen membeli produk AMDK galon AQUA.

Green Tsrust berpengaruh terhadap Customer Loyalty pada produk AMDK galon merek AQUA di wilayah Serpong Utara. Hal ini berarti bahwa tingginya tingkat kepercayaan yang dimiliki konsumen dapat mempengaruhi loyalitas konsumen. Semakin tinggi tingkat kepercayaan konsumen terhadap produk AMDK galon AQUA maka konsumen akan semakin loyal dengan produk AMDK galon AQUA. Konsumen yang memiliki tingkat kepercayaan yang tinggi tehadap suatu produk akan menunjukkan keloyalitasannya dengan cara diantaranya memberikan rekomendasi mengenai produk AMDK galon AQUA kepada orang lain, berkunjung berulang kali, bahkan menunjukkan kekebalan untuk tidak tertarik dengan produk AMDK merek lain yang mengeluarkan produk yang sejenis dengan merek AQUA.

Saran. Bagi PT Golden Mississipi, untuk menciptakan reputasi yang baik terhadap produk AQUA khususnya, perusahaan harus dengan cermat dan tepat dalam melakukan strategi yang dimiliki, tentunya dengan selalu dan mengedepankan aspek lingkungan. Tujuannya agar konsumen dapat dengan mudah mengetahui dan mengerti atas apa yang dilakukan perusahaan terhadap produk yang dihasilkan, terlebih dalam hal yang berkaitan dengan unsur green marketing.

Untuk penelitian selanjutnya, dapat ditambahkan variabel-variabel lain yang dapat mempengaruhi tingkat loyalitas konsumenpada produk AMDK galon merek AQUA. Sehingga penelitian selanjutnya dapat membantu pihak PT Golden Mississipi agar dapat mengetahui faktor apa saja selain green trust yang dapat menjadika konsumen loyal pada produk AMDK galon merek AQUA yang ada. 


\section{DAFTAR RUJUKAN}

Chen, Y-S. (2009) "The Drivers of Green Brand Equity: Green Brand Image, Green Satisfaction, and Green Trust", Journal of Business Ethics, 93 (2), 307-319.

Chang, N-J., \& Fong, C-M. (2010) Green product quality, green corporate image, green customer satisfaction, and green customer loyalty. Journal of Business Management, 4(13), 2836-2844.

Chen, Y-S. (2013) Towards green trust: The influences of green perceived quality, green perceived risk, and green satisfaction. Journal of Management Decision, 51 (1), 63 82.

Chen, Y-S., Lin, C-Y., \& Weng, C-S. (2015) The Influence of Environmental Friendliness on Green Trust: The Mediation Effects of Green Satisfaction and Green Perceived Quality. Journal of open access sustainability, 7, 10135-10152

Ferdinand, Augusty. (2006) Structural Equation Modeling dalam Penelitian Manajemen. Semarang: Badan Penerbit Universitas Diponegoro.

,(2014) Metode Penelitian Manajemen Pedoman Penelitian untuk Penulisan Skripsi, Tesis dan Disertasi Ilmu Manajemen. Semarang: Badan Penerbit Universitas Diponegoro.

Ghozali, Imam. (2008) Model Persamaan: Konsep dan Aplikasi dengan Program AMOS 16. Semarang: Badan Penerbit UNDIP

Ghozali, Imam \& Fuad. (2005) Structural Equation Modelling: Teori, Konsep, dan Aplikasi dengan Program Lisrel 8.54. Semarang: Badan Penerbit Universitas Diponegoro.

Ghozali, Imam. (2008) Structural Equation Modeling dengan LISREL 8.80. Semarang: Universitas Diponegoro.

Ghozali, Imam. (2011) Model Persamaan Struktural. Semarang: Badan Penerbit Universitas Diponegoro.

Hair, J. F., et al. (2007) Multivariate Data Analysis 6th Edition. New Jersey: Pearson Education Inc.

Hayu, R Suthia. (2014) "The Influence of Satisfaction, Trust and Price of Consumer Loyalty on Green product”, Management Insight, 9 (1), 30-44.

Hermawan, Budi. (2011). "Pengaruh Kualitas Produk Terhadap Kepuasan, Reputasi MErek Dan Loyalitas Konsumen Jamu Tolak Angin PT.SIDO MUNCUL", Jurnal Manajemen Teori dan Terapan, 4 (2).

Kalalo R.E. (2013) "Customer Relationship Management dan Kualitas Pelayanan Pengaruhnya Terhadap Loyalitas Konsumen PT. Matahari Dept. Store", Jurnal EMBA, 1 (4), 1553-1561.

Kaufmann, H.R., Panni, M.F.A.K., \& Orphanidou,Y. (2012) "Factors Affecting Consumers' Green Purchasing Behavior: An Integrated Conceptual Framework", Amfiteatru Economic, XIV (31).

Kotler P \& Gary Armstrong. (2006) Prinsip-prinsip Pemasaran, Jilid I, Edisi 12, Jakarta: Erlangga.

Marknesis, Tim. (2009) Customer Satisfaction and Beyond. Yogyakarta: Marknesis.

Massie, Phailander V. (2013) "Ekuitas Merek Pengaruhnya terhadap Keputusan Pembelian XL Mobile Data Service di Kota Manado". Jurnal EMBA, 1 (4), $1474-$ 1481. 
Noegroho, O.A., Suharyono, dan Kumadji, S. (2013) "Pengaruh Experiential Marketing Dan Brand Trust Terhadap Kepuasan Pelanggan Dan Loyalitas Pelanggan", Jurnal Administrasi Bisnis (JAB), 6 (2).

Noor, Juliansyah. (2011) Metode Penelitian: Skripsi, Tesis, Disertasi, dan Karya Ilmiah. Edisi Pertama. Jakarta: Prenadameda Group.

Pechyiam,C. \& Jaroenwanit, P. (2014) "The Factors Affecting Green Brand Equity of Electronic Products in Thailand", The Macrotheme Review, 3 (9).

Pratama, M. A. (2014) Pengaruh Green Perceived Value, Green Perceived Risk dan Green Trust terhadap Green Purchase Intention Lampu Philips LED di Surabaya. Jurnal Ilmiah Mahasiswa Universitas Surabaya, 3 (1), 1-20.

Priyatno, Dwi. (2010) Paham Analisa Statistik Data Dengan SPSS, Jakarta: PT. Buku Seru.

PT. Bank Mandiri (Persero) Tbk. (2015) Air Minum Dalam Kemasan (AMDK). Industry Update Office of Chief Economist, Volume 11 Juni 2015 (diakses pada 25 September 2015)

Punitha, S \& Rasdi R Mohd. (2013) "Corporate Social Responsibility: Adoption of Green Marketing by Hotel Industry”, Asian Social Sciene, 9 (17), 1911-2025.

Rambing.P.R. (2015) “The Influence Of Green Marketing Strategy Towards Purchasing Decision With Brand Image As An Intervening Variable On AQUA Bottled Drinking Water In Manado", Jurnal EMBA, 3 (2), 235-245.

Saleem, M. A., Khan, M. A., \& Alam, S. (2015) Antecedents of Green Purchase Intentions: Evidence from Customers of Electronics Products from Multan District. Journal of European Academic Research, (II), 14900-14916.

Sangadji E. Mamang \& Sopiah. (2013) Perilaku Konsumen. CV OFFSET: Yogyakarta.

Saputri E Marheni dan Pranata R Tutut. (2014) "Pengaruh Brand Image Terhadap Kesetiaan Pengguna Smartphone Iphone", Jurnal Sosioteknologi, 13. (3).

Sciffman, L. G., \& Leslie Lazar Kanuk. (2008) Perilaku Konsumen. Jakarta: PT Indeks.

Sekaran, Umar. (2006) Metodologi Penelitian untuk Bisnis. Jakarta: Salemba Empat.

Shih, S. P., Yu, S., \& Tseng, H. C. (2015) "The Study of Consumers' Buying Behavior and Consumer Satisfaction in Beverages Industry in Tainan, Taiwan". Journal of Economics, Business and Management, 3 (3), 391-394.

Siswanto, B. (2010) "Perkembangan Konsep dan Penelitian Green Marketing: Analisis Pustaka", Jurnal Ilmiah Manajemen Bisnis, 10 (1), 63-70.

Sugiyono. (2009) Metode Penelitian Bisnis. Bandung: CV. Alfabeta. ,(2011) Metode Penelitian kuantitatif kualitatif. Bandung: Alfabeta ,(2014) Metode Penelitian Manajemen. Bandung: Alfabeta.

Sumarwan, Ujang, dkk. (2012) Riset Pemasaran dan Konsumen. Bogor: PT Penerbit IPB Press.

Sumarwan, Ujang. (2013) Perilaku Konsumen: Teori dan Penerapannya Dalam Pemasaran: Pendekatan Praktis Disertai Himpunan Jurnal Penelitian. Bogor Selatan: Penerbit Ghalia Indonesia.

Sunyoto, Danang, (2013) Perilaku Konsumen, Yogyakarta: CAPS (Center Of Academic Publishing Service).

Supranto J \& Nandan Limakrisna. (2013) Perilaku Konsumen dan Strategi Pemasaran Untuk Memenangkan Persaingan Bisnis, Jakarta: Mitra Wacana Media.

Suryani, Tatik. (2013) Perilaku Konsumen di Era Internet Implikasinya Pada Strategi Pemasaran. Graha Ilmu: Yogyakarta. 
Umar, Husein. (2005) Riset Pemasaran dan Perilaku Konsumen. Jakarta: PT Gramedia Pustaka.

Wu, S-I. \&Yen-Jou Chen. (2014) "The Impact of Green Marketing and Perceived Innovation on Purchase Intention for Green Products". International Journal of Marketing Studies, 6 (5), 81-100. 